E-ISSN. 2685-7650

Vol. 1 No. 1 (2019), pp 27-35

DOI: https://doi.org/10.33366/jkn.v1i1.7

\title{
Peran Program Rojhek Cingur Radio Nada Fm dalam Melestarikan Budaya Lokal di Sumenep Madura
}

\author{
Khoiruz Zein ${ }^{1}$, Sulih Indra Dewi ${ }^{2}$ \\ ${ }^{1,2}$ Program Studi Ilmu Komunikasi, Universitas Tribhuwana Tunggadewi \\ Email: k.zhaen@gmail.com
}

\begin{abstract}
The Rojhek Cingur program was one of the Nada FM radio broadcast programs produced and broadcasted for the first time in 2016. The program discussed the values and local culture of Madura delivered by the people, which was then combined with the news of cultural issues developing across the people. This research used descriptive qualitative type. The main informant of the study were the broadcaster of the Rojhek Cingur program and the Nada FM radio station manager. The data collection technique of this research was carried out by interview, documentation and observation. While the data analysis technique consisted of data collection, data reduction and data presentation. The data validation used data triangulation. The result showed that the Rojhek Cingur program was one of the Nada FM radio programs discussed cultural values. The role of Rojhek Cingur Nada FM radio program were (1) Rojhek Cingur was a rehabilitation of Madura culture, (2) Rojhek Cingur was an education and cultural socialization, and (3) Rojhek Cingur was an unifying media. The pattern of communication between broadcaster and Rojhek Cingur program listeners were (1) Two-way communication patterns (two way traffic communicatios), and (2) Multidirectional communication patterns.
\end{abstract}

Keywords: Mass Communication, Rujak Cingur program, Local Culture.

\begin{abstract}
Abstrak: Program Rojhek Cingur merupakan salah satu program radio Nada FM yang diproduksi dan disiarkan pertama kali pada tahun 2016. Program ini menggali tentang nilai-nilai budaya lokal Madura. Dibawakan oleh penyiar melalui kabar-kabar dari masyarakat yang kemudian dipadukan dengan hasil bidikan reporter demi relevannya isu atau berita yang beredar di masyarakat. Penelitian ini dilakukan di Radio lokal Nada FM Sumenep Madura dengan menggunakan metode penelitian kualitatif deskriptif. Informan utama didalam penelitian ini yaitu tiga penyiar dan Station Manager Nada FM. Teknik pengumpulan data ini dilakukan dengan cara wawancara, dokumentasi dan observasi. Teknik analisis data dalam penelitian ini meliputi pengumpulan data, reduksi data dan penyajian data. Validasi data penelitian ini menggunakan triangulasi data. Dari hasil penelitian ini Rojhek Cingur merupakan salah satu program Nada FM yang khusus dalam mengobrolkan nilai-nilai kebudayan. Peran program radio Rojhek Cingur di Nada FM adalah (1) Rojhek Cingur sebagai rehabilitas budaya Madura (2) Rojhek Cingur sebagai pendidikan dan sosialisai budaya. (3) Rojhek Cingur sebagai media pemersatu. Pola komunikasi antara penyiar dengan pendengar program Radio Rojhek Cingur Nada FM adalah (1) Pola komunikasi dua arah (two way traffic communicatios), dan (2) Pola komunikasi multi arah.
\end{abstract}

Kata Kunci : Komunikasi Massa, Rujak Cingur, Budaya Lokal.

\section{Pendahuluan}

Radio merupakan media komunikasi yang dapat menyampaikan pesan-pesan dan informasi pada masyarakat. Selain murah dan meriah radio saat ini semakin mudah diakses karena hampir semua gadget/handphone. Selain itu, radio mampu menemani pendengar di segala situasi dan kondisi, bahkan apabila si pendengar sambil mengerjakan banyak aktivitas (Susanti, 2015). Akibat perkembangan teknologi elektronik, yang merancang proses komunikasi antar manusia, maka dikembangkanlah siaran radio (Yanti, 2017). Ada berbagai macam yang disiarkan dalam 


\section{Jurnal Komunikasi Nusantara}

E-ISSN. 2685-7650

Vol. 1 No. 1 (2019), pp 27-35

DOI: https://doi.org/10.33366/jkn.v1i1.7

radio mulai dari beragam acara radio sampai iklan. Umumnya, radio memiliki beberapa program siaran seperti, di antaranya, siara berita, dialog interaktif, siara olahraga, siara kebudayaan, siaran pendidikan, dan musik (Harumike \& Huda, 2018). Oleh sebab itu, radio, di samping berbagai fungsi dan tujuan lainnya, dimanfaatkan untuk menyampaikan berbagai berita atau pesan-pesan yang ditujukan kepada masyarakat atau khalayak ramai (Nasor, 2017). Selain dari itu juga radio dapat mempengaruhi prilaku seseorang yang mendengar. Acara-acara yang disiarkan oleh radio semakin lama semakin bervariatif seiring dengan perkembangan zaman yang semakin maju dan ketat dalam persaingannya.

Di era modern ini media massa radio memiliki nilai tawar terhadap para pendengarnya hal itu di sesuaikan dengan porsi kebutuhan dari para pendengarnya. Selain daripada itu, karena siaran radio adalah bisnis telinga, maka berbagai elemen yang berkaitan dengan siaran harus menarik perhatian masyarakat (Rosalia, 2012). Dengan demikian, hal itu menjadikan media massa radio tetap menjalankan fungsinya sebagai media yang cerdas, mendidik, menghibur, informasi, dan pendidikan. Kemasan-kemasan program yang menarik merupakan metode yang perlu di update terus agar supaya radio tetap mengungguli dari media-media massa lainya. Dengan demikian maka radio akan tetap eksis tanpa terkikis oleh media-media lainnya.

Sesuai amanat UU No. 32/2002 tentang penyiaran yang telah dirancang oleh Komisi Penyiaran Indonesia (KPI) bersama komisi I DPR membahas maklumat tentang siaran radio nasional harus berahir tahun 2005 serta mengenai peraturan pemerintah tentang lembaga penyiaran swasta yang melarang siaran radio nasional. Artinya jangkauan radio akan dibatasi (kpi, 2010). Tidak mengherankan apabila ada yang menyebut bahwa sekarang ini adalah era radio lokal.

Radio Nada FM adalah radio yang memiliki segmentasi multi segment, radio ini sangat berbeda jauh dengan radio-radio yang mempunyai segment tertentu pada umumnya, walaupun begitu radio ini mempunyai ciri khas yang kemudian menjadi kekuatan dalam pemutaran musik atau lagu dari berbagai jenis keroncong, pop, rock, dan musik-musik tradisional Madura yang sangat banyak diminati oleh para penikmat Nada (sebutan untuk pendengarnya) melalui progranprogram menarik, menghibur, dan mendidik, radio ini juga mempunyai kelemahan dalam bidang perpolitikan Sumenep yang sangat rendah sekali dalam pemberitaan, talk show tentang perpolitikan, dan lain sebagainya. Radio ini juga memiliki kepedulian yang sangat tinggi terhadap kebudayaan yang ada di kota Sumenep mulai dari makanan, pakaian dan bahasa walaupun pelestarian ini masih belum maksimal secara keseluruhan, oleh sebab itu peneliti tertarik untuk kemudian membantu meminimalisir tingkat kemerosotan budaya lokal Sumenep melalui program radio Rojhek Cingur Nada FM yang kemudian nantinya akan dilakukan perbandingan antara teori dan study yang ada dilapangan. Tujuan dalam penelitian ini untuk mengetahui peran Program Radio Rojhek Cingur di Nada FM untuk mempertahankan budaya lokal Sumenep Madura. Dan untuk mengetahui pola komunikasi antara penyiar dengan pendengarProgram Radio Rojhek Cingur Nada FM untuk melestarikan budaya lokal di Sumenep Madura. Penelitian ini menggunakan teori konvergensi simbolik Ernest Bormann (dalam Suryadi, 2010) menyatakan teori konvergensi simbolik adalah teori umum yang mengupas fenomena pertukaran pesan yang memunculkan kesadaran kelompok sehinga berimplikasi pada hadirnya makna, motif, dan perasaan bersama. 


\section{Jurnal Komunikasi Nusantara}

E-ISSN. 2685-7650

Vol. 1 No. 1 (2019), pp 27-35

DOI: https://doi.org/10.33366/jkn.v1i1.7

\section{Metode Penelitian}

Penelitian ini menggunakan pendekatan kualitatif. Pendekatan kualitatif ini diambil karena peneliti berusaha menelaah atau menganalisa budaya lokal yang sudah memudar sebab budaya global. Pendekatan kualitatif yaitu sebuah prosedur penelitian yang menghasilkan data deskriptif berupa kata - kata tertulis atau lisan dari orang-orang dan perilaku yang dapat diamati. Penelitian ini menggunakan analisis deskriptif, yaitu suatu analisis yang memberikan gambaran mengenai suatu objek dalam bentuk kalimat berdasarkan judul penelitain yang telah dipilih.

Data diperoleh dari dua sumber yaitu data primer dan data sekunder (Sugiyono, 2012). Teknik pemililihan informan yang digunakan dalam penelitian ini adalah teknik purposive. Menurut Moleong (2011:225) menyatakan bahwa "Penentuan informan yang lain juga tetap hatihati, yaitu harus purposive, seimbang, dan disesuaikan dengan tujuan serta hakikat penelitian kualitatif. Yang menjadi Informan harus subjek dan betul-betul paham tentang masalah yang dikehendaki dan dapat dipercaya oleh peneliti.

Lokasi penelitian ini dilakukan di Radio Nada Jl. KH. Mansyur 65 A, Sumenep Madura. Dalam penelitian ini yang menjadi subjek penelitian adalah program Rojhek Cingor Nada FM dalam melestarikan budaya lokal Sumenep. Data dikumpulkan melalui teknik wawancara, dokumentasi dan observasi.

\section{Hasil dan Pembahasan}

\section{Pola Komunikasi Penyiar dan Pendengar Program Rojhek Cingur}

Pola komunikasi adalah bentuk atau pola hubungan antara dua orang atau lebih dalam proses pengiriman dan penerimaan pesan yang mengaitkan dua komponen, yaitu gambaran atau rencana yang meliputi langkah-langkah pada suatu aktifitas dengan komponen-komponen yang merupakan bagian penting atas terjadinya hubungan komunikasi antar manusia atau kelompok dan organisasi, sehingga pesan yang dimaksud dapat dipahami (Hendri Gunawan, 2013). Pola komunikasi adalah bentuk atau pola hubungan antara dua orang atau lebih dalam proses mengkaitkan dua komponen atau lebih dalam proses mengaitkan dua komponen yaitu gambaran atau rencana yang menjadi langkah-langkah pada suatu aktifitas dengan komponen-komponen yang merupakan bagian penting atas terjadinya hubungan antar organisasi ataupun juga manusia. Pola komunikasi berisi

Pola komunikasi penyiar dengan pendengar program Rojhek Cingur ini menggunakan bahasa Madura tingkat kedua (Engki-Enten) dari bahasa Madura tingkat pertama (Enjek -Iye) dengan tujuan pendengar dapat memakai bahasa Madura mulai dari tingkatan yang paling rendah hingga tingkatan yang paling halus. Lain dari itu semakin seringnya pemakaian bahasa Madura maka semakin kecil pula terkikisnya budaya bahasa di suatu daerah

Program Rojhek Cingur merupakan salah satu program radio Nada FM yang memiliki banyak pendengar. Program ini tidak pernah sepi dari penelepon. Oleh sebab itu, berikut ini merupakan pola komunikasi yang berlangsung di dalam program Rojhek Cingur yang juga menjadi salah satu faktor program tersebut diminati banyak pendengar.

1. Pola komunikasi dua arah (Two way traffic communication)

Pola komunikasi dua arah merupakan pola komunikasi yang berlangsung di dalam program Rojhek Cingur sebelum kemasan program tersebut dirubah ke dalam kemasan tor-cator santai keluarga. Pola komunikasi ini hanya terjadi antara penyiar dengan pendengar, tidak bagi 


\section{Jurnal Komunikasi Nusantara}

\section{E-ISSN. 2685-7650}

Vol. 1 No. 1 (2019), pp 27-35

DOI: https://doi.org/10.33366/jkn.v1i1.7

pendengar dengan pendengar yang lain. Komunikasi ini terjadi bila seorang komunikatoir menyampaikan pesan kepada seorang komunikan melalui media, kemudian pesna tersebut kepada komunikan dan terjadi peristiwa umpan balik (Hartono, 2016). Posisi sentral dalam program ini adalah penyiar. Penyiar menjadi satu-satunya orang yang terus berkomunikasi dengan beberapa pendengar dalam waktu yang tidak bersamaan. Pola komunikasi dua arah dalam program tersebut dapat digambarkan sebagai berikut.

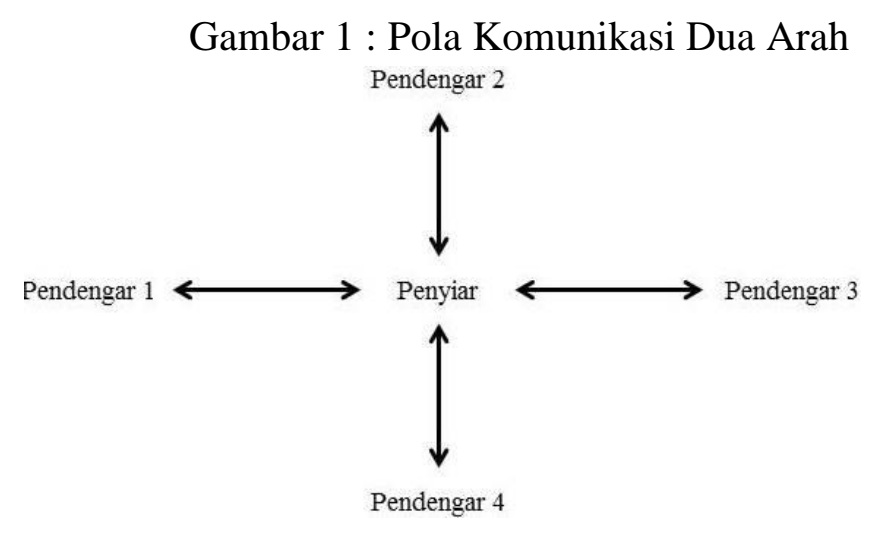

Dalam pola ini semua pihak terlibat. Dengan pengertian lain, dalam berinteraksi, penyiar dan pendengar secara bersama-sama terlibat di dalamnya. Dalam konteks ini, pola komunikasi ini dimulai oleh penyiar sebagai titik sentral komunikasi. Hal ini bisa dilihat dari penyiar yang membuka program tersebut dan kemudian mengajak para pendengar 1,2,3 dan 4 untuk ikut bergabung dengan cara menelepon bergantian dan menyampaikan permasalahan-permasalahan terkait perkembangan budaya-budaya lokal yang ada di Madura khususnya Sumenep. Secara lebih jelas, pola ini bisa digambarkan dengan seorang penyiar yang memandu program tersebut, lalu kemudian terjadi komunikasi interaktif antara penyiar dengan pendengar.

Pola interaktif atau komunikasi dua arah ini terjadi dalam bentuk opini dan tanggapan yang dilakukan penyiar dan pendengar. Komunikasi yang dilakukan penyiar terhadap pendengarnya pertama kali yaitu menyapanya kemudian mengajaknya bergabung untuk menanggapi atau memberikan opini serta memberikan pandangan terhadap suatu topik yang sedang diangkat atau juga bisa memberikan informasi lalulintas maupun keluhan sarana publik. Dengan istilah lain, dalam suatu waktu penyiar dapat menjadi komunikator dan pendengar sebagai komunikan, dan pada waktu yang lain, pendengar dapat menjadi komunikator dan penyiar menjadi komunikan.

Arti lain komunikasi dua arah diatas adalah penyiar merupakan garda terdepan dalam membentengi atau menanggapi suatu informasi mengenai budaya yang beredar di masyarakat, lalu kemudian pendengar satu hingga ke empat diatas merupakan objek sumber berita yang berkembang dimasyarakat, pada intinya penyiar disini tidak memberikan sekatan ataupun batasan pendapat,keluhan ataupun aspirasi dari semua pendengar sekaligus penelpon tersebut. Sehingganya di menit akhir program kembali ke penyiar yang kemudian menyimpulkan dari semua pendapat, keluhan, aspirasi dari pendengar sekaligus penelpon.

2. Pola komunikasi multi arah

Pola komunikasi multi arah ini, dikutip dari Onong Uchjana Effendy, biasanya berlangung dalam satu kelompok yang lebih banyak di mana komunikator dan komunikan akan saling bertukar 


\section{Jurnal Komunikasi Nusantara}

\section{E-ISSN. 2685-7650}

Vol. 1 No. 1 (2019), pp 27-35

DOI: https://doi.org/10.33366/jkn.v1i1.7

pikiran secara dialogis (Joko, 2013). dalam kegiatan talkshow. Kemasan program Rojhek Cingur tidak jauh berbeda dengan talkshow, hanya saja disebut dengan istilah tor-cator santai. Di dalam pola komunikasi ini, antara penyiar 1 (tamu), penyiar 2 dan 3 (keluarga), dan pendengar terjadi komunikasi dan interaksi satu sama lain sehingga komunikasi tidak bertitik fokus pada salah satu atau tidak ada yang bertindak sebagai pihak yang mendominasi komunikasi. Pola komunikasi multi arah dalam program Rojhek Cingur dapat digambarkan sebagai berikut.

Gambar 2 : Pola Komunikasi Multi Arah

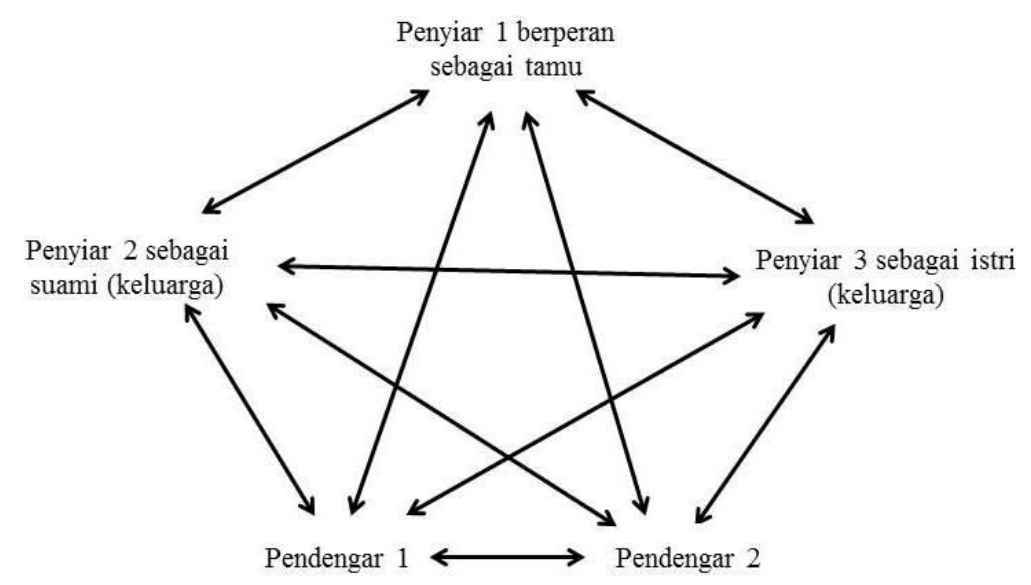

Di dalam pola komunikasi yang seperti ini, ide atau gagasan yang diperbincangkan tidak selalu berasal dari penyiar 1 (tamu) atau penyiar 2 dan 3 (keluarga). Kadang topik perbincangan datang dari pendengar yang menanggapi sebuah opini sebelumnya dengan opni baru yang relevan tetapi menarik untuk dibahas lebih dalam. Dengan demikian, komunikasi tidak terpusat pada penyiar karena dalam pola komunikasi yang seperti itu semua elemen menjadi partner, sehingga tidak terjadi upaya untuk saling mendominasi perbincangan.

Komunikasi multi arah disini bertujuan untuk memicu ataupun merangsang gagasan atau pendapat dari pendengar. Aktor tamu dan keluarga (suami istri) disini tetap sebagai komunikator yang saling mengisi dan melengkapi didalam tema yang di angkat saat siaran, aktor tamu dan keluarga biasanya berbincang-bincang untuk menghangatkan suasana sebelum interaktif berlangsung, aktor tamu dan keluarga (suami istri) menduduki peran fiktif pro dan kontranya masing-masing. Dengan itu sehingganya dapat memancing emosional pendengar untuk kemudian ikut andil memberikan berbagai macam pendapat. Kemudian penyiar dapat menarik benang merah dari beragai argumen pendengar yang sudah disampaikan melalui satu bahasa daerah Madura dengan berbagai macam intonasi dari keseluruhan desa yang berbeda-beda.

\section{Peran Program Rojhek Cingur Terhadap Budaya Lokal Sumenep}

Program Rojhek Cingur Nada FM disiarkan satu kali dalam seminggu. Program ini dibawakan oleh tiga penyiar, yang mana satu sama lain saling melengkapi dalam memberikan tanggapan terhadap gagasan maupun permasalahan yang disampaikan masyarakat. Keberhasilan seorang penyiar bisa dilihat dari sejauh mana pendengar dengan setia mendengarkan program tersebut dan banyak yang berinteraksi dalam program tersebut. Dalam konteks program Rojhek 


\section{Jurnal Komunikasi Nusantara}

E-ISSN. 2685-7650

Vol. 1 No. 1 (2019), pp 27-35

DOI: https://doi.org/10.33366/jkn.v1i1.7

Cingur ini, para pendengar yang mendengarkan dan yang berinteraksi dengan penyiar dengan cepat memahami konten yang sedang dibicarakan.

Program Rojhek Cingur merupakan salah satu program Nada FM yang bisa mempersatukan Masyarakat. Hal itu dibuktikan ketika pendengar bergabung (interaktif) kemudian menyampaikan pendapat atau aspirasi ataupun segala pertanyaan-pertanyaan tentang budaya di daerahnya masingmasing, setelah itu penyiar (Wawan, Mery dan Bayu) menanggapi segala pendapat juga menjawab dari pertanyaan-pertanyaan yang sudah di pertanyakan oleh pendengar, ketika sudah semuanya terjawab oleh penyiar maka penyiar membuka sesi kirim salam untuk penelpon. Penelpon biasanya memberikan salam kepada penelpon lainnya baik yang sudah bergabung maupun belum bergabung, penelpon yang mengirimkan salam ini menggunakan bahasa Madura tingkatan tengah yaitu Engghi-Enten, begitu pula untuk penelpon selanjutnya.

Rojhek Cingur merupakan salah satu program Nada FM khusus dalam mengobrolkan nilainilai kebudayan yang berkembang di masyarakat. Salah satu contoh topik yang sudah dibawakan yaitu Tor-Cator Madure Se Ampon Elang (Penyampaian bahasa Madura yang sudah hilang) dan Tolong-Pettolong (tolong menolong) Dari deskripsi tersebut dapat dijabarkan bahwa sudah tentu program ini memiliki peran yang signifikan dalam melestarikan budaya lokal Madura. Beberapa budaya yang dimaksud dalam konteks ini adalah budaya penggunaan bahasa Madura dan pelestarian budaya tolong-pettolong atau gotong royong. Adapun peran konkret program Rojhek Cingur ini dapat dijabarkan sebagai berikut:

a. Rojhek Cingur sebagai recalling bahasa Madura

Bahasa adalah kebiasaan. Semakin terbiasa bahasa itu digunakan maka semakin kuat pula bahasa itu dalam suatu masyarakat. Begitu pula sebaliknya. Apabila bahasa Madura semakin jarang digunakan, maka akan semakin dekat bahasa itu lenyap dari tengah masyarakat Madura terutama generasi muda Sumenep. Belakangan ini, bahasa Madura sudah banyak dilupakan oleh generasi muda Sumenep. Semakin minimnya penggunaan bahasa Madura di kalangan generasi muda diduga lantaran lingkungan di mana mereka tinggal tidak lagi membiasakan berbahasa daerah, sehingga dari tahun ke tahun bahasa yang menjadi kebanggaan masyarakat Madura kian terkikis seiring perkembangan zaman (M. Fahrul, 2016).

Semakin jarangnya penggunaan bahasa Madura tidak serta-merta akan melenyapkan bahasa tersebut, melainkan akan ada kondisi di mana masyarakat akan lupa beberapa kata dalam bahasa Madura. Sangat ironis sekali apabila orang Madura lupa terhadap bahasa sendiri. Oleh sebab itu, penggunaan bahasa Madura mulai level Iye-Enja', Engghi-Enten, hingga Engghi-Bhunten di dalam program Rojhek Cingur akan membangkitkan kembali kesadaran masyarakat untuk melestarikan bahasa tersebut. Melalui proses berinteraksi di dalam program Rojhek Cingur, penyiar dan pendengar saling bertukar pesan mengenai budaya lokal Sumenep terutama penggunaan bahasa Madura.

Ketika salah satu pendengar menelepon dan bertukar pesan dengan penyiar, pendengar yang lain sedang menyimak pertukaran pesan tersebut. Proses tersebut kemudian menciptakan realitas yang secara kolektif dirasakan oleh para pendengar, sehingga realitas tersebut menjadi realitas bersama sebagaimana yang terkandung dalam teori konvergensi simbolik.

Dalam konteks ini, teori konvergensi simbolik terlihat dari bagaimana pesan-pesan budaya, terutama penggunaan bahasa Madura yang ada di dalam program Rojhek Cingur, dapat 


\section{Jurnal Komunikasi Nusantara}

E-ISSN. 2685-7650

Vol. 1 No. 1 (2019), pp 27-35

DOI: https://doi.org/10.33366/jkn.v1i1.7

membangun kesadaran simbolik bersama antara pihak pengelola radio Nada FM terutama para penyiar program Rojhek Cingur dan pendengar untuk melestarikan penggunaan bahasa Madura. Dampak atau pengaruh program tersebut adalah bagaimana masyarakat Sumenep mulai sadar bahwa seiring zaman yang terus berkembang, bahasa Madura harus selalu digunakan agar tetap terpelihara kelestariannya. Selain daripada itu, para pendengar yang menelepon mau tidak mau juga menggunakan bahasa Madura yang baik dan benar, dan ini secara tidak langsung terbangun di dalam alam bawah sadar para pendengar untuk menggunakan bahasa Madura, bukan hanya pada saat berintetraksi di dalam program Rojhek Cingur, melainkan juga pada saat berinteraksi dengan masyarakat di lingkungan sosial.

Dalam konteks yang lain, program Rojhek Cingur dapat membangkitkan kesadaran masyarakat secara sosiologis bahwa hidup membutuhkan orang lain, sehingga saling membantu menjadi salah satu elemen utama interaksi sosial masyarakat terus terjalin dan kokoh. Interaksi sosial yang kuat dalam suatu kelompok masyarakat akan menguatkan masyarakat itu sendiri untuk terus maju dan mempertahankan identitasnya sebagai masyarakat Madura, yang memiliki budaya dan nilai-nilai kearifan lokal yang agung.

b. Rojhek Cingur sebagai rehabilitas budaya Madura.

Bahasa adalah kebiasaan. Semakin terbiasa bahasa itu digunakan maka semakin kuat pula bahasa itu dalam suatu masyarakat. Begitu pula sebaliknya. Apabila bahasa Madura semakin jarang digunakan, maka akan semakin dekat bahasa itu lenyap dari tengah masyarakat Madura terutama generasi muda Sumenep. Belakangan ini, bahasa Madura sudah banyak dilupakan oleh generasi muda Sumenep.

Oleh sebab itu, penggunaan bahasa Madura mulai level Iye-Enja', Engghi-Enten, hingga Engghi-Bhunten di dalam program Rojhek Cingur akan membangkitkan kembali kesadaran masyarakat untuk melestarikan bahasa tersebut. Melalui proses berinteraksi di dalam program Rojhek Cingur, penyiar dan pendengar saling bertukar pesan mengenai budaya lokal Sumenep terutama penggunaan bahasa Madura.

Ketika salah satu pendengar menelepon dan bertukar pesan dengan penyiar, pendengar yang lain sedang menyimak pertukaran pesan tersebut. Proses tersebut kemudian menciptakan realitas yang secara kolektif dirasakan oleh para pendengar, sehingga realitas tersebut menjadi realitas bersama sebagaimana yang terkandung dalam teori konvergensi simbolik.

c. Rojhek Cingur sebagai pengedukasi dan sosialisai budaya.

Rojhek Cingur Nada FM memiliki peran yang sangat signifikan dalam mensosialisasikan dan mengedukasi masyarakat mengenai nilai-nilai budaya lokal yang ada di Madura. Hal ini tentu disebabkan oleh semakin maraknya budaya westernisasi, sehingga perlu menghadirkan kembali program-program yang dapat memberikan pendidikan terhadap masyarakat. Keberadaan budaya sangat penting bagi identitas masyarakat, sehingga keberlangsungan sebuah budaya harus terus dilakukan dengan cara mewariskannya dari waktu ke waktu dan dari generasi ke generasi.

Program Rojhek Cingur, dengan salah satu temanya yaitu Tor-Ator Madhure Se Ampon Elang (penyampaian bahasa Madura yang sudah hilang), dimana terdapat alokasi waktu bagi pendengar yang mau berinteraski melalui telepon untuk menyampaikan permasalahanpermasalahan akan pentingnya budaya, merupakan satu reaslisasi program yang sangat bermanfaat bagi seluruh elemen masyarakat Madura, terutama bagi orang tua untuk terus menyampaikan 


\section{Jurnal Komunikasi Nusantara}

E-ISSN. 2685-7650

Vol. 1 No. 1 (2019), pp 27-35

DOI: https://doi.org/10.33366/jkn.v1i1.7

sosialisasi dan edukasi budaya-budaya lokal yang ada di Madura terutama Sumenep dan kesediaan generasi muda untuk dapat menerima dan mempelajari budaya-budaya lokal yang berkembang di sekitar.

Media sebagai pengedukasi dan sosialisasi budaya tersebut juga dinyatakan oleh Baskoro P. Bahwa media massa merupakan bentuk komunikasi dan rekreasi yang menjangkau masyarakat secara luas sehingga pesan informasi yang sama dapat diterima secara serentak dan sesaat. Media massa terdiri dari media cetak (surat kabar, brosur, baleho, buku, majalah, tabloid) dan media elektronik (radio, televisi, video, film, piringan hitam, kaset, CD/DVD). Media massa diidentifikasikan sebagai media sosialisasi yang berpengaruh pula terhadap perilaku masyarakat. d. Rojhek Cingur Sebagai Media Pemersatu

Rojhek Cingur mengandung beragam konten kebudyaaan. Beberapa di antaranya, sebagaimana yang sudah dijelaskan sebelumnya, adalah budaya penggunaaan bahasa madura dan budaya tolong-pettolong. program Rojhek Cingur memiliki peran yang signifikan dalam melakukan sosialisasi budaya-budaya lokal Sumenep. Dalam konteks ini, sosialisasi tidak hanya menyampaikan kembali budaya-budaya yang sudah nyaris terkikis, tetapi juga menanamkan penetahuan bahwa banyak nilai-nilai budaya yang di miliki oleh msyarakat Sumenep.

Kesadaran akan keberadaan budaya-budaya lokal yang ada di lingkungan sekitar akan membangkitkan perasaan memiliki yang lebih besar secara kolektif sehingga kondisi ini akan melahirkan perasaan saling memiliki perasaan dan kepedulian bersama terhadap pelestarian budaya lokal. Kondisi ini, secara lebih lanjut, akan melahirkan perilaku untuk saling menjaga sehingga akan lahir perasaan untuk bersatu, bersama-sama atau bahu-membahu menjaga dan melestarikan budaya lokal.

\section{Kesimpulan}

Peran program Rojhek Cingur merupakan salah satu program yang mengkonsep atau berkonten tentang budaya lokal yang ada di Sumenep, hal ini dibuktikan dengan antusias pendengar yang tidak sedikit ikut andil dalam interaktif program Rojhek Cingur. Program Rojhek Cingur dapat membentuk solidaritas sesama masyarakat Sumenep dengan saling membagi informasi terkait budaya-budaya yang mulai berkembang ataupun mulai menyimpang dari alur yang sebagaimana mestinya, dari berbagai informasi pendengar sekaligus solusi dari penyiar maka secara tidak sadar program Rojhek Cingur dapat memberikan kontribusi untuk mengembalikan budaya lokal Sumenep yang sudah mulai terkikis.

Pola komunikasi penyiar dengan pendengar disini mengunakan bahasa Madura tingkat kedua (Engki Enten) dari bahasa tingkat pertama (Iye Enjek). Ada dua pola komunikasi dari Program Rojhek Cingur disini yang pertama, pola komunikasi dua arah dimana penyiar menjadi titik tumpu utama dari berbagai informasi pendengar. Yang kedua pola komunikasi multi arah, pola komunikasi multi arah disini tidak mesti bertumpu pada penyiar ataupun pendengar, bisa saja dari penyiar ataupun pendengar dalam satu topik yang di angkat. Kadang topik perbincangan datang dari pendengar yang menanggapi sebuah opini sebelumnya dengan opni baru yang relevan tetapi menarik untuk dibahas lebih dalam. 


\section{Jurnal Komunikasi Nusantara}

\section{E-ISSN. 2685-7650}

Vol. 1 No. 1 (2019), pp 27-35

DOI: https://doi.org/10.33366/jkn.v1i1.7

\section{Daftar Pustaka}

Hartono, R. (2016). Pola Komunikasi di Pesantren : Studi tentang Model Komunikasi antara Kiai, Ustadz, dan Santri di Pondok Pesantren TMI Al-Amien Prenduan. Al-Balagh: Jurnal Dakwah Dan Komunikasi, 1(1), 67-100. https://doi.org/10.22515/balagh.v1i1.60

Harumike, Y. D. N., \& Huda, A. M. (2018). THE MODEL OF PUBLIC INFORMATION OPENNESS "Interactive Broadcast of Memorandum of Understanding (MoU) between Blitar Government and Village Government in the Supervision of the Village Fund Allocation's Implementation." Journal of Academic Research and Sciences (JARES), 1(1), 207-222. https://doi.org/10.30957/jares.v3i2.489

Gunawan, H. (2013). Jenis Pola Komunikasi Orang Tua Dengan Anak Perokok Aktif Di Desa Jembayan Kecamatan Loa Kulu Kabupaten Kutai Kartanegara. Ilmu Komunikasi, 1(3), 218-233.

Joko, S. (2013). Etnografi Komunikasi Pada Tiga Generasi Anggota Perkumpulan Marga ANG di Bagansiapi-api. Journal of Chemical Information and Modeling, 6(1), 51-59. https://doi.org/10.1017/CBO9781107415324.004

Kpi.go.id 2002. Komisi penyiaran indonesia, penyiaran. Diakses 22 juli 2018 dari kpi.go.id/index.php/id/undang-undang.

Fahrul, M., Sjafari, I. (2016). Generasi Muda Suemenep Tidak Bia Gunakan Bahasa Madura dengan Baik. Www.Cendananews.Com. https://www.cendananews.com/2016/11/generasi-muda-sumenep-tidak-bisa-gunakanbahasa-madura-dengan-baik.html

Moleong, J. L. (2011). Metodologi Penelitian Kualitatif Edisi Revisi. Bandung. Remaja Rosdakarya.

Nasor, M. (2017). Optimalisasi Fungsi radio sebagai media dakwah, Al-Adyan: Jurnal Studi Lintas Agama, Vol. 12, No. 1, hal. 105-128. https://doi.org/10.24042/ajsla.v12i1.1447

Rosalia, N. (2012). Faktor-faktor Penting Daya Tarik Stasiun Radio Bagi Pendengar Radio Di Kota Semarang. Interaksi: Jurnal Ilmu Komunikasi, 1(1), 77-86. https://doi.org/10.14710/INTERAKSI.1.1.77-86

Sugiyono. (2012). Metode Penelitian Kuantitatif Kualitatif dan R\&D. Alfabeta.

Susanti, F. (2015). Pengaruh Bauran Promosi Terhadap Keputusan Klien Dalam Memilih Radio Carano Sebagai Media Promosi Iklan. Jurnal KBP, 3(1), 104-115. https://doi.org/10.31227/osf.io/b9ws7

Yanti, D. E. (2017). Alih Kode dan Campur Kode Siaran Rado 94.4 FM d Rado Lampung dan Implkasnya Terhadap Pembelajaran Bahasa dan Sastra Indonesia di SMA. Skripsi, 5(2), 113. 